\title{
Positron Emission Tomography Detection of Distant Metastatic or Synchronous Disease in Patients with Locally Advanced Rectal Cancer Receiving Preoperative Chemoradiation
}

Caio S. R. Nahas, MD, ${ }^{1}$ Timothy Akhurst, MD ${ }^{2}$ Henry Yeung, MD, ${ }^{2}$ Tobias Leibold, MD, ${ }^{1}$ Ellen Riedel, MA, ${ }^{3}$ Arnold J. Markowitz, MD, ${ }^{4}$ Bruce D. Minsky, MD, ${ }^{5}$ Philip B. Paty, MD, Martin R. Weiser, MD, ${ }^{1}$ Larissa K. Temple, MD, ${ }^{1}$ W. Douglas Wong, MD, ${ }^{1}$ Steven M. Larson, MD, ${ }^{6}$ and José G. Guillem, MD ${ }^{1}$

\author{
${ }^{1}$ Department of Surgery, Memorial Sloan-Kettering Cancer Center, New York, NY, USA \\ ${ }^{2}$ Department of Nuclear Medicine, Memorial Sloan-Kettering Cancer Center, New York, NY, USA \\ ${ }^{3}$ Department of Epidemiology \& Biostatistics, Memorial Sloan-Kettering Cancer Center, New York, NY, USA \\ ${ }^{4}$ Department of Gastroenterology, Memorial Sloan-Kettering Cancer Center, New York, NY, USA \\ ${ }^{5}$ Radiation Oncology, Memorial Sloan-Kettering Cancer Center, New York, NY, USA \\ ${ }^{6}$ Department of Medicine, Memorial Sloan-Kettering Cancer Center, New York, NY, USA
}

Erratum to: $10.1245 / \mathrm{s} 10434-007-9626-\mathrm{y}$

Annals of Surgical Oncology

Tobias Leibold, MD, was inadvertently not included in the byline of the article, "Positron Emission Tomography Detection of Distant Metastatic or Synchronous Disease in Patients with Locally Advanced Rectal Cancer Receiving Preoperative Chemoradiation" by Nahas et al (DOI 10.1245/s10434-007-9626-y). $\mathrm{He}$ is a co-author of this article.
The complete and correct byline of this article, including Dr. Leibold, is as follows:

Caio S.R. Nahas, Timothy Akhurst, Henry Yeung, Tobias Leibold, Ellen Riedel, Arnold J. Markowitz, Bruce D. Minsky, Philip B. Paty, Martin R. Weiser, Larissa K. Temple, W. Douglas Wong, Steven M. Larson, and Jose G. Guillem

Received October 31, 2007; accepted October 31, 2007; published online January 23, 2008.

The online version of the original article can be found under doi: 10.1245/s10434-007-9626-y

Address correspondence and reprint requests to: José G. Guillem, MD; E-mail: guillemj@mskcc.org

Published by Springer Science+Business Media, LLC $\odot 2008$ The Society of Surgical Oncology, Inc. 